Acta Pó́tica 37•2

julio-diciembre

$2016(87-115)$

Gerardo Bustamante BermúdeZ

Universidad Autónoma de la Ciudad de México

gerardbb81@hotmail.com

\title{
Juan Bañuelos y Abigael Bohórquez: la poesía como resistencia y representación social ${ }^{1}$
}

\section{Juan Bañuelos and Abigael Bohórquez: Poetry as Resistance and Social Representation}

En el presente artículo se estudian algunos poemas de los poetas mexicanos Juan Bañuelos y Abigael Bohórquez, dos escritores que compartieron, además de amistad, afinidades y preocupaciones temáticas a partir del convulso contexto nacional e internacional de los años sesenta y setenta del siglo pasado. Con algunas herramientas de la sociología de la literatura, se pretende señalar la producción contextual de estos escritores poco estudiados por la crítica literaria especializada y que ofrecen desde la subjetividad poética su versión y compromiso con la función social de la poesía en momentos emergentes en la historia cultural del siglo xx.

PALABRAS CLAVE: poesía, representación, contexto, resistencia, escritura.

This article studies poems by Mexican poets Juan Bañuelos and Abigal Bohórquez who, in addition to friendship, shared thematic affinities and concerns relating to the tumultuous national and international contexts of the 1960s and 1970s. Through the sociology of literature, this article examines the contextual production of these two writers, whose work has received little attention from

${ }^{1}$ Este artículo es uno de los productos comprometidos en mi estancia posdoctoral en el Posgrado en Teoría Literaria, de la Universidad Autónoma Metropolitana, Unidad Iztapalapa. 
specialized literary critics. Furthermore, this study aims to illustrate how these authors offer their versions of and commitment to the social function of poetry in key moments of $20^{\text {th }}$ century cultural history.

KEYWORDS: poetry, representation, context, resistance, writing.

Fecha de recepción: 24 de noviembre de 2015

Fecha de aceptación: 26 de febrero de 2016

País mío no existes

sólo eres una mala silueta mía

una palabra que le creí al enemigo.

Roque DaLton

—n la "Introducción" a la antología Poesía mexicana II. 1915-1979, Carlos Monsiváis señala que la década de los sesenta en la lírica nacional estuvo marcada por la asimilación de las voces de Pablo Neruda y César Vallejo, así como de la influencia de Ernesto Cardenal y Nicanor Parra. En el ámbito internacional, el cronista refiere los nombres de Pound, Eliot, Mallarmé y Ginsberg como autores clásicos que los poetas mexicanos de los sesenta leen y comentan. Sobre la "poesía comprometida", Monsiváis afirma: "Los sucesos del realismo socialista, al ver en la poesía el ariete que derrumbará al imperialismo, sólo magnifican y deforman la consigna de Huidobro ('No cantes el pueblo, poeta, hazlo llegar al poder') no sin una agitada inmersión en un machismo estereofónico" (1979: XLV). Líneas más adelante, afirma el autor:

Las proporciones son concretas: que en la poesía aparezca la vida cotidiana, que se gane en cercanía lo que se pierde en elegancia clásica, que irrumpa (molesto y divertido y vulgar y efímero) lo cotidiano. Tal revolución no acaba de consumarse, quedan truncas o inconexas las ideas en torno a esta "factura" del poema, pero dan origen a otra posición receptiva: que los lectores acudan, no [...] para enaltecerse con lo inefable o sucumbir de gozo ante el "espejo de la armonía", sino para recuperar 
intuiciones comunes, volverlas sutiles, sedimentarlas, conferirle prestigio a la reflexión sobre lo inmediato, y sin prejuicios reverenciales o monumentos declarados [...]

La poesía se aproxima a la historia cuando la historia empieza a manifestarse con violencia en el país (XLVI, XLVIII).

¿Estética de lo social disidente? ¿Poesía y representación? Estos binomios irrumpen en la poesía mexicana de los años sesenta de forma sostenida. La clasificación de poesía de tema social en el ámbito literario ha causado debates incluso entre los mismos escritores, quienes con frecuencia rechazan la clasificación porque en algunos de los casos se puede pensar que se trata de un panfleto. Los lectores y la crítica literaria también han mostrado sus reservas respecto a la escritura de representación, pues la arraigada tradición del estructuralismo de los años setenta rechaza toda propuesta que pretenda leer un texto literario en los márgenes de la semántica discursiva interna. La estética de la recepción y la sociología de la literatura, por su parte, han posicionado miradas alrededor del contexto de producción/publicación de la obra, la lectura biográfica e ideológica del escritor.

Muy a pesar de la discusión añeja en la teoría literaria, la historia de la literatura, al menos a partir del siglo $\mathrm{xx}-\mathrm{y}$ particularmente a partir de la Primera Guerra Mundial—, está llena de ejemplos y etiquetas que forman y forjan sin querer una tradición temática en donde texto literario (propuesta estética) y contexto político-social se concatenan. Términos como "novela de la Guerra Civil española", "literatura del exilio", "narrativa del Holocausto", "novela de la dictadura en Latinoamérica", "poesía de protesta" o "poesía comprometida" han sido denominaciones que sirven en la historia literaria para enmarcar una época convulsa que lleva al creador a no posicionarse desde un tema y estética "escapista" o desarticulada del contexto y discursos emergentes. El mismo teatro del absurdo, por ejemplo, se posiciona como una estética que se opone al realismo por parecerle que el horror, las injusticias y la miseria deben ser nombradas desde la antítesis de la lógica. Frente a la realidad descarnada de la posguerra, se recurre a la abolición de la razón, pues la guerra y todo lo que implica se resemantiza desde un arte de la resistencia que obliga a un replanteamiento de las ideas filosóficas 
del enciclopedismo y el positivismo como fuentes de razón y progreso social.

¿Para quién escribe el poeta? ¿Cuál es su auditorio? ¿En momentos convulsos, son los jóvenes estudiantes, los obreros, campesinos o aquellos grupos organizados para la resistencia los que leen y se incide en su ideología o comportamiento? Al paso de las décadas, pareciera que las voces líricas en el ámbito nacional, más allá de sus propuestas poéticas, a las que hay que estudiar por su factura estética, han quedado como el testimonio disidente de una utopía en el sentido de que la poesía quizás pueda servir como un medio de comunicación ideológica en términos artísticos, pero no incide, al menos de forma decisiva, en los cambios sociales y políticos de las prácticas sociales. Al lado de la participación activa en las marchas, el poeta contribuye desde la creación a cuestionar, mostrar o protestar, de forma subjetiva e incluso fragmentaria, las estructuras dominantes de los grupos hegemónicos respecto de los intereses de las clases populares.

El nacimiento de la sociología de la literatura en los años setenta del siglo xx (Lotman, Silbermann, Robin, Goldmann, Cros, entre otros), permitió a ciertos escritores interesados en el tema de la representación social producir una serie de textos que valen más allá de su calidad literaria, pues suponen un diálogo contextual e histórico desde el espacio de la literatura como disciplina que convive con la sociología, la historia y la antropología. En el caso de Latinoamérica, los escritores Pablo Neruda, César Vallejo, Ernesto Cardenal, Oliverio Girondo o Mario Benedetti, por mencionar sólo algunos nombres, tomaron la palabra poética como una forma de resistencia o solidaridad con los pueblos. En diálogo con estos creadores, en México, las voces del poeta chiapaneco Juan Bañuelos y la del sonorense Abigael Bohórquez se corresponden en la medida en que ambos plantean un discurso lírico-político que se opone al tratamiento mediático de los grandes acontecimientos nacionales e internacionales que convulsionan no sólo la paz social, sino la condición humana misma: la guerra de Vietnam, la proliferación de las guerrillas centroamericanas, el conflicto de los campesinos y luchadores sociales en México, su repudio hacia las dictaduras en Latinoamérica y el Caribe, así como la función comprometida del poeta en momentos cruciales en donde los temas de la contemplación interior 
y el amor deben combinarse con la solidaridad humana y la protesta. Así, a través de la creación se evidencia, se protesta y se reflejan los comportamientos políticos y sociales que lesionan la tranquilidad social, el bienestar colectivo e incluso el derecho a tener una patria, sobre todo en Latinoamérica, donde los términos "nación" o "país" tienen una concepción particular desde las independencias nacionales iniciadas en el siglo XIX.

La sociología de la literatura sostiene que hay textos literarios que remiten a un referente o contexto que puede leerse desde la denotación, en tanto que el hecho semiótico o literario dentro del texto es lo que permite diferenciar la propuesta literaria respecto de otros tipos de discursos como el análisis sociológico de una realidad circundante. La subjetividad literaria en este sentido, a decir de Edmon Cros, se diferencia de otras prácticas discursivas "que operan en el marco de una sociedad dada: sermones, cartas pastorales, sínodos, catecismos, rituales, reglamentos, estatutos de hospitales, normas policiales, testimonios [...] [y] exigen igualmente que se les examine fuera de la función denotativa (16). Un texto literario difícilmente tiene una intención aleccionadora o moral, ya que opera principalmente a través de la realización estética. Lo que sí puede hacer es mostrar una visión de la realidad desde la recreación y la subjetividad del lenguaje artístico. Así, la propuesta literaria que propicia una visión de mundo, a pesar de que se trate de un sujeto (en este caso lírico) que enuncia desde el singular, representa también una conciencia del grupo social con el que se solidariza ya que, aunque se trata de una abstracción, cuando la clase social tiene una visión de mundo similar, dicha mirada identifica la voz enunciadora con el destinatario. De esta relación, la visión de mundo personal se comparte, se hace "transindividual", en términos de Goldmann.

El arte poético puede, como en los casos aquí estudiados, presentar elementos ideológicos cuyo estudio adyacente permita conocer la visión, experiencia, episodio biográfico e incluso la posición del creador dentro y fuera del canon artístico. La ideología del creador en momentos de contingencia política se manifiesta, ya que de acuerdo con Henri Lefèbvre, "toda obra de arte contiene elementos ideológicos (las ideas del autor, de su tiempo, de su clase), mezcladas por otra parte y a menudo con las ideas de otros tiempos, de otras clases, de otros individuos" 
(154). Para Lefèbvre, el verdadero arte es una forma de conocimiento a la vez que se combina con un elemento de ilusión, ya que al ser presencia es también emoción. Así, para este autor, las propuestas artísticas forman la superestructura que acompaña las manifestaciones sociales dentro de un esquema más profundo que es la estructura, tal como lo entiende la escuela marxista. Como superestructura entenderemos las manifestaciones culturales, entre ellas el arte, que dan soporte y contribuyen a la manifestación ideológica del tiempo, espacio y condiciones históricas de vida de los creadores y su medio.

En el caso del siglo xx, el triunfo de la Revolución rusa en 1917, así como las revoluciones encaminadas a instaurar regímenes de carácter socialista en países como Bulgaria, Hungría, Albania, Rumania, Polonia, China, Vietnam del Norte y Corea, se traducen como una política de la resistencia hacia el imperialismo de corte colonialista y capitalista. En el caso de Cuba, la revolución iniciada en 1959 significó un paradigma para las posibilidades de cambio en el Caribe y América Latina, principalmente en Chile, en donde el triunfo de la Unidad Popular en 1971 contempló los inicios del socialismo en Latinoamérica, aunque con el derrocamiento de Salvador Allende el proyecto se vio interrumpido por el inicio de la dictadura.

Juan Bañuelos...

“;Oh libertad, Tu nombre en mi país / Se dice hambre!

En 1960 y bajo el título colectivo La espiga amotinada, se dan a conocer como grupo literario e ideológico los jóvenes poetas Juan Bañuelos, Óscar Oliva, Jaime Augusto Shelley, Eraclio Zepeda y Jaime Labastida. Con la influencia de la poesía moderna, particularmente la anglosajona, permea en estos poetas la idea de la escritura como espacio de libertad.

A decir de Octavio Paz, Bañuelos (Tuxtla Gutiérrez, Chiapas, 6 de octubre de 1932) es el Trueno del grupo, en la medida en que su "poesía es poderosa pero su peligro no es la dispersión sino el ruido: la retórica de la fuerza" (29). A pesar de haberse adscrito al famoso grupo "La espiga amotinada", Bañuelos ha sido poco estudiado por la crítica especializada. En 2012, el Fondo de Cultura Económica reunió su obra 
poética bajo el título Vivo, eso sucede, en el que agrupa siete libros ya publicados, además de su primer poemario que permanecía inédito. En la presentación al tomo, el poeta introduce un texto escrito en 1960 en el que señala la importancia que representa en el espacio de la poesía tener una actitud revolucionaria, más allá del esnobismo literario. Poeta al que le tocó vivir lo que él llama "los años del desorden", en alusión a los conflictos nacionales e internacionales de los años sesenta y setenta, la poesía de Juan Bañuelos se nutre de una realidad subjetiva que aterriza en el espacio de lo literario; participa en actos políticos de resistencia, su poética se instaura como la voz de la hermandad y la solidaridad a través del referente contextual crítico de las políticas de la desigualdad, el exterminio humano y la pobreza de las clases trabajadoras. Sobre la labor artística, Bañuelos anota:

Nadie es verdaderamente artista hasta que no se libra de la mediocridad del ambiente, de la vanidad y del entusiasmo barato. La poesía de hoy debe estar orientada como una "violencia organizada" en contra del lenguaje poético y el cotidiano, que están al servicio de una clase en decadencia, la que hace que esos lenguajes sean retóricos y conservadores. Es una necesidad psicológica y social, y no el gusto exagerado de perfección o esnobismo, lo que debe obligarnos a saquear el tesoro del idioma, a buscar la palabra justa (9).

Juan Bañuelos se ocupa en términos generales del amor, el erotismo, la naturaleza mexicana, particularmente la chiapaneca, pero también sobre la labor del poeta dentro de la sociedad; las huelgas, los movimientos nacionales e internacionales bélicos, las guerrillas, la migración de los centroamericanos como resultado de las guerras civiles en El Salvador y Honduras. Cultiva las formas del soneto, el versículo, el verso libre y el aforismo. La carrera literaria de Bañuelos es concomitante con su disidencia política que, a decir de Efrén Ortiz Domínguez, "se ve sometido Juan a partir de la defensa que hace de la integridad física, política y cultural de los pueblos indoamericanos contemporáneos, actitud que le ha llevado a confrontar no sólo al poder público del país, sino a todo un sistema que subraya las diferencias socioculturales" ("Sublime abyección"). 
Un aspecto particular y recurrente en los primeros tres libros de Bañuelos es la confesión lírica de los episodios de pobreza que vive el creador:

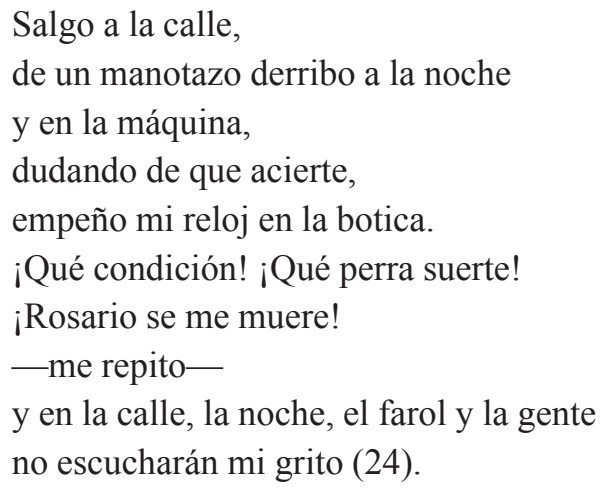

De la producción lírica del poeta, en este artículo sólo comentaremos algunos poemas de la colección Escribo en las paredes (1960), Espejo humeante (1968) y No consta en actas (1979), que nos permiten trazar un esquema de preocupaciones y representaciones sociales y políticas de la época en la que Bañuelos se observa como un trabajador de la palabra al servicio del pueblo, en una suerte de cronista del ambiente miserable y repulsivo que lee en los diarios, observa en la televisión o vive en las calles.

En el poema "Profecía inmediata", Bañuelos se pregunta sobre la verdadera función del poeta y la sinceridad que debe guardar el texto literario en momentos en los que el horror de lo que sucede escapa a la representación que pudiera hacerse. La poesía no es suficiente, tampoco el llanto, ni la rabia. El poeta cambia el registro del poema en papel y opta por escribir en las paredes, quizás con la intención de llegar al pueblo:

No sirve ya el papel.

No sirve el llanto.

Escribo en las paredes (39).

La protesta a través de la poesía es la forma a la que recurre el yo lírico para crear conciencia social, al menos en sí mismo. Aunque en 
ocasiones los poemas de Bañuelos no refieren el acontecimiento que es objeto de denuncia, al hacerlo de forma general deja para las nuevas generaciones la tarea de actualizar el poema. En el soneto "No hablo de mí, de todos hablo", el poeta se lamenta por el hambre, la pena y el llanto del pueblo. Su arma y contribución social es la poesía: "Amo este pueblo y este amor levanto", dice en el último verso del segundo cuarteto, y en los dos tercetos enfatiza su relación con la escritura en esos días terribles en donde la protesta es necesaria porque el poeta advierte la desesperanza.

Se hincha mi pecho y saltan los botones

de mi camisa. Silbo. Doy alarmas.

Y el viento se levanta de los llanos.

Oíd: golpeando puertas y portones

escribo y hablo: son éstas mis armas.

Y ésta es mi patria. Y éstas son mis manos (61).

Juan Bañuelos registra en su poesía acontecimientos como la hambruna de los pueblos, el asesinato de luchadores sociales, ya sean anónimos o mediáticos, como es el caso de Ernesto, el Che Guevara, asesinado en Bolivia en 1967 y a quien el poeta homenajea en "Fusil, hoja que conmueve a todo el árbol". Bañuelos se admite como parte del pueblo, va a las marchas, se solidariza a través de la escritura con los obreros, adopta el discurso de la colectividad y lo hace poesía, como en el poema "Huelga de hambre", poema extenso, dividido en cinco partes que Bañuelos escribe con motivo de una manifestación permanente afuera de la Academia de San Carlos a finales de 1959, en donde se pide la libertad de los presos políticos de México. En este poema se describen las calles del Centro Histórico con su bullicio y mercaderes; contrasta el anonimato de los manifestantes frente a los ojos de los parroquianos indiferentes, en cambio, denuncia las miradas vigilantes de la policía hacia todo aquel que se manifiesta por las calles: obreros, ferrocarrileros, hambrientos y demás ciudadanos vigilados. Como forma de contraste ante el anonimato, Bañuelos asume su compromiso con la palabra desde la enunciación del yo de un ciudadano, hijo de una patria que ha 
sido sometida a una larga cadena de afrentas. Ante cualquier posible interrogatorio policial, el poeta se revela a sí mismo:

Las palabras son hijas de la vida.

Sufren, paren; también tienen sus muertos.

Y en la honda capital de la miseria

las armé de fusiles y de verbos

(en esta patria muda, perseguida, donde hasta el aire mismo va a dolernos).

Yo fui el autor.

Lo que suena a dolor me suena a pueblo.

Nací en el Sur. Mi nombre:

Juan Bañuelos (80).

El poeta registra la rabia, presta su voz al guerrillero fusilado, no escatima palabras para el odio y la tristeza por los crímenes y miserias a las que son sometidos los más pobres dentro del aparato económico y político que confina a la masa a la servidumbre.

Del poemario Espejo humeante, la sección "Espalda tatuada de hábitos terrestres" se compone de catorce poemas en los que la voz lírica va incluyendo episodios de guerra, protesta o guerrilla a nivel nacional e internacional. En el primer caso, Bañuelos vuelca su protesta frente a la memoria por los acontecimientos trágicos de Hiroshima, ocurridos el 6 de agosto de 1945, con la intención de aniquilar a Japón e instaurar en el poder colonialista a los Estados Unidos. La bomba atómica es el acontecimiento de la física nuclear más trágico del siglo xx, ya que agrupó al Estado, a la industria y a los científicos al servicio de la guerra. La reacción nuclear fue el mecanismo esperado para debilitar a los países del eje (Japón, Alemania e Italia) y al proyecto socialista de Rusia; sin embargo, la explosión nuclear en Hiroshima contabilizó al menos setenta mil muertos de forma inmediata y otros ochenta mil que fallecieron en los siguientes días a la explosión como efecto de la radiación nuclear. El episodio de Hiroshima y Nagasaki ha quedado en la historia internacional como una tragedia de lesa humanidad que pone en evidencia la destrucción del medio ambiente, la deshumanización del hombre, el poder político y la complicidad de la ciencia al servicio 
de la destrucción. Bajo el esquema de un caligrama, Bañuelos recurre a la memoria personal y colectiva para rememorar la explosión:

No cambia el día.

Es la monótona égloga

del tiempo. Un hongo
de silencio
que
su
be
del
abismo
y se disuelve
en la memoria (104).

Por su parte, el poema "Sala de espera" recurre a la referencia hospitalaria (el poeta se siente herido) para denunciar la guerra en Vietnam, particularmente el bombardeo con napalm, ocurrido el 8 de junio de 1972 y que, nuevamente toma como víctimas al pueblo. Lo mismo da que se trate de un acontecimiento bélico internacional que una guerra civil en la que el imperio de la dictadura instaura el horror, el crimen y la represión absoluta frente a cualquier movimiento de protesta, como fue el caso de República Dominicana en manos del sanguinario Rafael Leónidas Trujillo, quien ocupó el poder de 1930 a 1938 y de 1942 a 1952. Al poeta le interesa hacer la historia de la infamia; se solidariza con el dolor, recurre a la memoria histórica y colectiva:

Toda la noche floté como el corcho de una botella golpeada por ahogados, tañí un árbol de crines transparentes, saludé repitiendo los mismos harapos y fui de sangre en sangre entre los que caían en Vietnam y en la Dominicana. En la sala sonaba un órgano de esponjas (105). 
Por su parte, en el poemario No consta en actas, Bañuelos se dedica a rememorar lo ocurrido en Tlatelolco, en octubre de 1968. El poemario, dedicado a Octavio Paz, dialoga con la historia prehispánica de Tlatelolco como lugar de ceremonia, batallas y sacrificios. Bañuelos lleva al siglo xx la historia de la infamia de aquello que, efectivamente, no constó en actas. La manifestación social reprimida y el crimen en la Plaza de las Tres Culturas se convierten en una "casa de niebla", en un espacio tenebroso. Los luchadores del pasado han quedado inscritos en piedra, pero en el presente de la enunciación, Bañuelos registra en papel la represión y el crimen. Así, los que antes eran guerreros y defensores de una cultura, ahora son víctimas o victimarios de un sistema que subordina al pueblo y lo enfrenta con los suyos:

¿Qué importan las granadas de gas

al borde del estruendo en las manos rapaces?

$\mathrm{Ah}$, soldados, granaderos, hermanitos inmundos

si fueran distintos en un país distinto

en donde la pobreza

afinada como un instrumento peligroso

no los hiciera doblemente abyectos (221).

En el poema "No consta en actas", Bañuelos va haciendo la crónica poética de la Marcha del silencio; habla sobre el allanamiento de morada como estrategia para sembrar el pánico social; también recuerda a las víctimas que se encuentran en los hospitales, a los que huyen o a los que son enterrados de forma clandestina para desaparecer las evidencias del crimen.

El poemario de Bañuelos presenta una visión catastrófica del hecho histórico nacional, pero sobre todo considera que a partir de este acontecimiento, México es un país sin lengua, una patria avejentada. En "Lienzo de las vejaciones", dice:

(Radiografia)

el 2 de octubre de 1968

envejecimos mil años

aunque todo sucedió

en una sola tarde. 
La memoria -vacía desde entonces

se llena a veces

de un vago tiempo humano (232).

En el poemario de Bañuelos, el 2 de octubre de 1968 queda registrado como el inicio de una época cruenta en México, sobre todo porque vendrá una oleada de represión de las guerrillas, como en el caso de Genaro Vázquez y Lucio Cabañas, ambos simpatizantes del Partido de los Pobres y acaecidos, el primero en febrero de 1972 y el segundo en diciembre de 1974.

Juan Bañuelos presenta su visión sobre la pobreza del pueblo en oposición a la opulencia de la clase política dirigente. Se trata de un país fragmentado, dolido y muerto en varios sentidos:

¿Por qué este derroche de fantasmas?

Soy de un país

donde se habla sin lengua

donde se baila

sin piernas,

donde las tumbas marchan

sobre sus propios pies (234).

\section{Abigael Bohórquez... "Ya no estoy para rosas"}

El poeta y dramaturgo sonorense Abigael Bohórquez (Caborca, Sonora, 12 de marzo de 1936, Hermosillo, Sonora, 28 de noviembre de1995), ${ }^{2}$ llamado por algunos críticos como "El poeta del Norte", ha sido dentro del panorama de la poesía y el teatro en México un autor marginal en el sentido de que su obra ha sido muy poco difundida, reeditada y estudiada, en gran medida porque no pertenece a generación literaria alguna, al

${ }^{2}$ Abigael Bohórquez García falleció de un infarto cardiaco en su departamento, en Hermosillo, entre el 25 y el 27 de noviembre. Aquí utilizamos la fecha del 28 debido a que ese día lo encontraron muerto. 
menos de las más visibles, aquellas que sostuvieron revistas, encuentros o publicaciones conjuntas en el centro del país.

En el campo literario, que un autor ingrese al canon significa que existe, que tiene un público lector, un número de críticos literarios y editoriales interesadas en su trabajo y que, además, es referido en los manuales literarios e incorporado en las antologías. En el caso particular del poeta sonorense, ninguna de las antologías clásicas de la poesía mexicana del siglo xx incorpora su producción. En el libro La literatura mexicana del siglo XX (1995), de José Luis Martínez y Christopher Domínguez Michael, no hay una sola mención al trabajo literario de Bohórquez. Lo mismo sucede en Poesía en movimiento (1966), texto antológico preparado por Octavio Paz, Alí Chumacero, José Emilio Pacheco y Homero Aridjis. Es comprensible la no inclusión de Bohórquez en este libro debido a que sus mejores poemas estaban por escribirse. Por su parte, en Ómnibus de la poesía mexicana (1971), compilación de Gabriel Zaid, tampoco se incluye al poeta, por lo que el nombre de Abigael Bohórquez ha quedado al margen de los grupos literarios que construyen y definen el canon. Más allá de la no incorporación del autor en una generación poética, lo mejor será juzgar su producción a la luz de lo que propone. Conviene entonces detenernos precisamente en sus propuestas literarias y estudiarlo por lo que sus propios textos significan desde los márgenes de la poesía mexicana y del diálogo divergente que establece con una tradición.

La obra poética del autor sonorense consta de trece libros. A mi juicio, podemos dividir su obra en tres momentos: 1). Poesía inicial, que abarca los libros Ensayos poéticos (1955) y Fe de Bautismo (1960), en donde habla sobre el amor, la naturaleza mexicana, la tristeza y el desamor. 2). Poesía de tema social y citadina/rural, compuesta por los libros Acta de confirmación (1966), Canción de amor y muerte por Rubén Jaramillo y otros poemas civiles (1967), Las amarras terrestres (1969) y Memoria en la Alta Milpa (1975), en donde se ocupa ampliamente del tema político y social no sólo de México sino en América Latina, con sus correspondientes escenarios de represión, abusos y abyección del poder político y económico. La Ciudad de México también ocupa un lugar privilegiado en cuanto a la representación que hace el poeta de estos espacios. Es precisamente este segundo momento en el que 
se observa la madurez lírica del poeta; no obstante, la crítica literaria y académica ignoró en su mayoría la contribución del autor sonorense. El tercer momento en su obra lo componen los libros Digo lo que amo (1976), Desierto mayor (1980), Abigaeles y poeniñimos (1990), Poesía en limpio. 1979-1988 (1990) y Navegación en Yoremito (1993), en donde habla sobre el tema homoerótico, tópicos infantiles, familiares y sobre el paso del tiempo. La obra póstuma consta de los siguientes títulos: Poesida (1996) y Poesía inédita (2005). En el primero, el autor se ocupa nuevamente del tema amoroso y sexual entre hombres pero, sobre todo, del homenaje a todos sus amigos muertos de sida, en tanto que en Poesía inédita, a través de la jitanjáfora, Bohórquez hace un homenaje a la cantante sinaloense Lola Beltrán, a quien tanto admiró.

Amén de lo anterior, conviene preguntarnos cuáles son las razones por las cuales se excluye de manera visible al poeta Abigael Bohórquez y se le impide su paso al panorama de la poesía mexicana de los años sesenta y setenta, cuando en estas décadas el autor produjo poemas prodigiosos como "Llanto por la muerte de un perro", "Menú para el generalísimo", "Acta de confirmación" o "Noche noche", cuatro de los mejores poemas del autor sonorense.

Es en los temas sociales en los que Bohórquez representa la abyección política, la miseria humana e incluso en los que hace referencia u homenajea a luchadores sociales como Rubén Jaramillo, pero también lleva al espacio de la poesía contextos adversos como las dictaduras en América Latina, Vietnam, Hiroshima y Nagasaki. En varios poemas, sobre todo en aquellos escritos y publicados en los años sesenta y setenta, el poeta hace la apología de una época convulsa, llena de injusticias sociales y de un futuro incierto. Si bien es cierto que autores como José Emilio Pacheco, Margarita Paz Paredes, Jaime Labastida, Óscar Oliva, Efraín Huerta y Rosario Castellanos escribieron poemas de tema político, sobre todo a partir de la matanza del 2 de octubre de 1968, el discurso de Bohórquez resulta aún más disidente; su poesía de puño y rabia se erige como el testimonio de un autor que es parte de los marginados y grita su dolor y protesta porque experimenta una solidaridad de clase; él mismo es parte de una colectividad; su función de poeta no reconocido en su momento lo vuelve vulnerable por excluido. 
En la rama del testimonio narrativo Los días y los años (1970), de Luis González de Alba y La noche de Tlatelolco (1971), de Elena Poniatowska se convirtieron en dos fuentes imprescindibles para entender el trágico acontecimiento del 68 en México. Quizás en el terreno de la poesía, la obra de Bohórquez tenga más diálogo con la de autores como Roque Dalton, Ernesto Cardenal, Alaíde Foppa, Nicanor Parra, e incluso con las voces de Víctor Jara y Violeta Parra, como cantores y poetas populares. La poética de Bohórquez vislumbra su compromiso social, ya que constantemente trata temas como la censura, la libertad de expresión, el circo político, con sus correspondientes injusticias sociales y los contextos caóticos del periodo de la Guerra Fría y la escena trágica de Vietnam y el México del 68.

Carlos Monsiváis se pregunta en "Notas sobre la cultura mexicana del siglo xx" si existe una cultura literaria después del 2 de octubre de 1968. Más allá del libro testimonial La noche de Tlatelolco de Poniatowska, considera el cronista que "La matanza de las Tres Culturas y el 68 no han dispuesto de tratamientos perceptivos y críticos y lo más común ha sido desplegar la tragedia sobre un fondo melodramático, o - actitud también en el mercado- convertirla en un episodio amarillista, gracias a la presunción de que el destino de los asesinatos es la nota roja" (2000: 1046). Monsiváis reconoce tres novelas emblemáticas posteriores al movimiento estudiantil de 1968: Lapsus (1971) de Héctor Manjarrez, Cadáver lleno de mundo (1971), de Jorge Aguilar Mora y Se está haciendo tarde (1973), de José Agustín. Nosotros insistimos en que la poesía de Bohórquez, intencionalmente borrada por Monsiváis debido a la animadversión que éste sentía por el poeta y dramaturgo, constituye una voz disidente que bien merece atención y requiere un estudio a fondo. ${ }^{3}$

3 El artista plástico y escultor Raymundo Frausto Guizar, amigo y discípulo de Bohórquez, refiere lo siguiente: "La enemistad con Monsiváis se da a mediados de los sesenta, pues en una reunión en la casa del escritor Carlos Eduardo Turón, en la zona Rosa, Bohórquez criticó a Monsiváis, le recriminó su actitud de intelectual de izquierda. El maestro nunca creyó en la izquierda mexicana, por el contrario, la atacó severamente. Ese fue el principal encono de Monsiváis: que un poeta como Bohórquez se lo haya dicho de frente" (entrevista con Raymundo Frausto, concedida al autor de este artículo el 19 de enero de 2015). Enrique Serna plantea una opinión similar sobre 
Evocar a Abigael Bohórquez es necesario desde el presente, pues se trata de hacer una revisión del concepto de "utopía" en el siglo xx, una época convulsa, llena de derrotas y muertes incluso ideológicas, marcada por traiciones a nivel nacional y con intereses imperialistas. La presencia poética de Bohórquez viene a replantear el concepto de "utopía" en el siglo xx en América Latina. Su posición no fue de izquierda; siempre actuó de forma autónoma, criticando incluso a esas izquierdas que excluyen de sus filas a los disidentes sexuales porque se piensa que no son útiles para la revolución. En su poesía está la figura del hombre que piensa y escribe sobre el hombre, de ahí que su compromiso con la poesía social sea casi exclusiva en México. Pocos poetas mexicanos de su tiempo actuaron con tanta responsabilidad social al llevar al terreno de la poesía las vidas de personajes casi anónimos como Rubén Jaramillo, gran personaje del periodo posrevolucionario. Abigael Bohórquez hace una disección de la política y las representaciones sociales en América Latina. Desde esta perspectiva, la disidencia política de Abigael Bohórquez le hizo pasar por las vicisitudes de su carrera literaria, además de las económicas; su compromiso con lo social tiene el sello de la consecuencia que supone utilizar la poesía como una artillería de pensamiento crítico en el que hace una revisión de las condiciones sociohistóricas del momento.

Bohórquez es de los pocos poetas en México que en su momento habló sobre el terrorismo de Estado, el imperialismo y la intervención imperialista estadounidense en Nicaragua, El Salvador, Honduras o Guatemala. De ideología socialista — aunque nunca fue militante-, el poeta repudia el golpe de Estado y la dictadura de Augusto Pinochet en Chile, iniciada en 1973, así como la sangrienta dictadura de Jorge Rafael Videla, en Argentina (1976-1981).

En su libro Genealogía de la soberbia intelectual (2013), Enrique Serna utiliza el término "intelectuales orgánicos" para hablar sobre los mecanismos que se instauran a través de las instituciones públicas porque, aduce, resulta imposible hacer una carrera fuera de ellas. Para estudiar la presencia literaria e incluso mediática de autores como Fernando

los intelectuales de izquierda en su libro Genealogía de la soberbia intelectual (2013), citado en el cuerpo de este trabajo. 
Benítez, Carlos Fuentes, Octavio Paz, Elena Poniatowska y otros más, Serna contextualiza y explica la relación de los intelectuales orgánicos en México, particularmente a partir de 1988:

Cuando un crítico pone en duda el valor literario de una vaca sagrada con pensión vitalicia, no sólo demerita una obra: denuncia un fraude a la nación [...] El intelectual orgánico puede ser un funcionario público respetable o un cómplice de tropelías dictatoriales, según la naturaleza del régimen al que sirva $[. .$.$] cuando la intelectualidad burocratizada$ encubre a un estado delincuencial, como sucedía en México, o cuando respalda a un régimen totalitario, como ocurrió con las dictaduras del bloque socialista, la élite mimada que disfruta privilegios inmerecidos pierde su bien más valioso: la credibilidad. Una vez roto ese canal de comunicación, la desconfianza impide cualquier intento de restablecer el diálogo con el público traicionado (162-163).

En el caso de Abigael Bohórquez, gran parte de sus libros se publicaron en editoriales de poca circulación. Las preguntas centrales que surgen para entender la poesía y difusión de tema social son: ¿cuáles son las razones por las que la difusión de la obra del autor fue en su momento casi nula? ¿El respaldo a un régimen supone la promoción de los artistas, el reconocimiento e incluso los premios? ¿Cómo funciona, quién dirige o mandata los postulados estéticos que hacen que un autor sea estudiado por la academia y la crítica especializada? ¿Qué lugar ocupa la poesía de tema social dentro de la obra en general de un autor, una época y un contexto?

En el libro Poesía rebelde en Latinoamérica (1978), Saúl Ibargoyen y Jorge Boccanera señalan que con frecuencia se piensa que este tipo de poesía es rebelde, contestataria, militante, protestataria o revolucionaria. Los autores antologan textos de autores de Latinoamérica y el Caribe que durante los años sesenta y setenta quedan unidos por el sentido de la protesta a través de la poesía.

La poesía de tema social es desde mi punto de vista un testimonio e ideología disidente que, a través del lenguaje - herramienta de comunicación y diálogo social- inscribe en el espacio literario un discurso de denuncia de injusticias y conflictos políticos de orden local, nacional o internacional. La poesía es un arma de resistencia a través del lenguaje 
y si bien es cierto que un producto literario no puede cambiar el sistema de injusticias, sí logra, a partir de ciertos recursos técnicos, retóricos e ideológicos, comunicar, dialogar con el lector, denunciar o interrogar acontecimientos sociales. La representación social a través de la poesía materializa la visión del mundo del yo lírico, así como su concepción de la justicia y la injusticia. El poeta que recurre a estos temas escribe para sí, pero también para su momento histórico. La noción del poeta apartado de la sociedad es una idea que se difumina fácilmente cuando el creador sale a las calles, observa, dialoga y participa. Ejemplos de poetas que trabajan con la sociedad en Latinoamérica hay muchos, al menos durante el caótico siglo xx: Roque Dalton, Ernesto Cardenal, Alaíde Foppa, Mario Benedetti, Pablo de Rokha o Pablo Neruda, por ejemplo. Este último recuerda en su libro de memorias, Confieso que he vivido, su encuentro con los trabajadores del mercado de la Vega Central, en la periferia de Santiago de Chile. Al dar una charla un tanto improvisada y al leer poemas de su libro España en el corazón, Neruda apunta:

La lectura duró más de una hora. Cuando me disponía a retirarme, uno de aquellos hombres se levantó. Era de los que llevaban el saco anudado alrededor de la cintura.

—Quiero agradecerle en nombre de todos — dijo en alta voz-. Quiero decirle, además, que nunca nada nos ha impresionado tanto.

Al terminar estas palabras estalló en un sollozo. Otros varios también lloraron. Salí a la calle entre miradas húmedas y rudos apretones de mano.

¿Puede un poeta ser el mismo después de haber pasado por estas pruebas de frío y fuego? (2004: 305).

¿Cuál es el compromiso del poeta con el pueblo? ¿La poesía de tema social comunica, hace más sensibles y críticos a quienes lo escuchan? ¿En qué medida lo hace? A decir del escritor ecuatoriano Miguel Donoso Pareja,

un poema, por muy revolucionarias que sean las ideas que expresa, no cambia la realidad. Podría impugnarla, cuestionarla, rechazarla y hasta desacreditarla, pero jamás cambiarla puesto que toda transformación revolucionaria implica una militancia política y una acción. Sí podrá, 
en cambio -aun expresando contenidos reaccionarios- revolucionar la poesía, si es que, en cuanto poema, se enfrenta a su propia naturaleza y la transforma (citado en Ibargoyen y Boccanera: 10).

La poesía de tema social en Latinoamérica presenta sus particularidades respecto a las propuestas estéticas y representaciones políticas y sociales nacionales, pero también todas estas tendencias están unidas por el tema de la exposición temática, la denuncia o el homenaje a los personajes que luchan en contra de un régimen que instaura el poder como recurso para legitimarse. La conexión intertextual de dos o más textos que se unen por la representación de un mismo tema social se llama "cotexto", según la nomenclatura usada por Régine Robin para aludir a los referentes intertextuales que forman un sistema de referentes temáticos que se concatenan y complementan, continúan o amplían el discurso ideológico en un texto literario.

Poesía y contexto sociopolítico son el resultado de lo que se vive en diferentes lugares de Latinoamérica durante el siglo xx. El texto poético adquiere un nuevo significante cuando se lee más allá de los márgenes de la literariedad formalista y desde una perspectiva sociopolítica, de ahí la importancia de referir los postulados de la sociología de la literatura como una opción de estudio del texto literario.

La sociología de la literatura propone centrar la atención e indagar más allá del "dentro del texto". Para estudiosos como Régine Robin, existe un "fuera del texto" que refiere la temporalidad, el mensaje y el espacio imaginario que está en el extratexto, es decir, en los márgenes de lo que el lector reconoce fuera de la obra literaria. Esta operación permite reinscribir dentro de la literatura el discurso social desde una perspectiva subjetiva que opera inicialmente dentro de los parámetros y permisividades que se da el creador para no convertir su texto en un panfleto o discurso historiográfico, pues la intención de un texto literario de tema social no puede ser la de fijar una versión histórica, ya que desde el primer momento, la mirada, el método de acercamiento al hecho social y el uso de recursos literarios impiden hablar de objetividad. Bajo esta perspectiva, el "dentro del texto" al que alude Robin resulta de la apreciación subjetiva del artista, en tanto que el "fuera del texto" permite sobre todo al lector indagar en los márgenes, épocas y circuns- 
tancias de producción y alusión de un periodo histórico al que se refiere un hecho literario. En todo caso, la objetividad puede darse cuando se analiza el "fuera del texto".

La preocupación del tema social en Abigael Bohórquez está presente desde sus primeras obras. En el caso particular del poema "Retablo indígena...", que pertenece al poemario Ensayos poéticos (1955), el autor, con plena conciencia de lo que supone el asunto indígena en México, plantea una visión de la miseria, la pobreza y la orfandad humana en una geografía calcinada por el abandono. A pesar de que en su madurez Bohórquez renegó de su primer libro, este poema destaca por los juegos de sinestesia para referir la tragedia de una mujer indígena y su hijo a punto de morir. La voz lírica se ubica como un espectador de ese "retablo" que contiene una historia "movible" y que se corresponde con la realidad indígena nacional. Cito el poema completo debido a que es casi desconocido:

Con su enagua roja,

trágicamente roja de rencores...

y su poncho negro,

para siempre teñido de tristeza,

trota la indita estéril de alegrías,

mientras indólicamente enmudecido

en sus espaldas,

el vástago,

un átomo paréceme de ausencia

bajo el atardecer de luces que se duermen

en el espejo de las aguas muertas...

Chisporrotea el sol ansiosamente,

y en los pies de la indita

hay un dejo de olvido estrangulante...

una lágrima seca

se prende a las pestañas desgarbadas

cual ave prisionera...

y su mirada

cual lánguido miraje de intenciones,

en sus oblicuos ojos se taladra 
cual un ligero vértigo de luna...

Colina arriba

trota la indita...

absorbiendo el paisaje en sus caderas

infantilmente estrechas

y mientras se quiebra el ídolo de piedra

en la bruma del tiempo, que encanece

gruñendo de impotencia,

en la ladera que peina matorrales

se levanta la cruz del misterio

en contraste angustioso...

Fe-esperanza.

Colina abajo

cual un pedazo de bronce acomplejado

trota la indita...

Y cual signos algebraicos

aparecen las estrellas en sus raras ecuaciones

de indolencia...

Mientras mírase abstraído, platicar con la distancia

el ojear del chilpayate...

$\mathrm{Y}$ en contraste con el negro firmamento

que se aburre de esmeralda

y quiere llegar a Dios,

se desliza la nativa

por las secas sementeras

que rumiando desprecios vanse quedando muertas

por amnesia de un olvidado ayer...

Ya no se ve la india!

y en las zarzas

se han quedado prendidos los colores

llenos de pesadumbre

de su enagua

trágicamente roja de rencores... (1955: 12)

En 1990 el poeta Abigael Bohórquez, entrevistado por Juana Reyes, refiere que en medio del contexto adverso nacional, "no pueden los poetas, como todos los artistas, evadirse, hacer literatura o poesía de 
ciencia ficción, cerrar los ojos a la realidad; tienen que derribar la Torre de Marfil y fundirse en la tragedia del hombre común, participar en la lucha por la desaparición de la injusticia. Creo que el artista verdadero debe darse a su gran obra, aquella que está hecha con la sangre y los huesos de los hombres" (10).

El compromiso de Abigael Bohórquez con la poesía, la representación social y la resistencia a través de la escritura comprometida se da desde 1960, cuando incorpora su magistral poema "Llanto por la muerte de un perro" en la colección Fe de bautismo. Después vendrán los libros marcadamente comprometidos respecto al tema social y la protesta por el acontecer nacional e internacional como Acta de confirmación (1966) y Canción de amor y muerte por Rubén Jaramillo y otros poemas civiles (1967). ${ }^{4}$ No será gratuito que la crítica literaria "autorizada" ignore casi por completo estos libros.

En 1975, Abigael Bohórquez publica Memoria en la Alta Milpa, un texto en donde habla sobre la geografía rural del Distrito Federal. Se ocupa también del tema homosexual en buena parte de estos poemas, aunque no olvida el asunto de la representación contextual del siglo Xx, tanto a nivel local, como nacional o internacional. Uno de esos textos es "Día franco", poema extenso y eminentemente musical en el que en el nivel fónico-fonológico el poeta construye una gran onomatopeya con énfasis en las sílabas oxítonas y en el encabalgamiento que da un sentido especial al poema debido a la forma en que se "juega" con la acentuación de las palabras. Para la construcción del poema, Bohórquez usa la onomatopeya con acierto para crear rimas alternadas.

"Día franco" posiciona la visión ácida del yo lírico que reacciona en contra de la tragedia en medio de los intereses mediáticos y políticos que instauran la política del "aquí no pasa nada" y en cambio mediatizan a través de la cultura del entretenimiento y la música popular, un fácil Carpe diem basado en el consumo, la felicidad, la fe en el gobierno y sus instituciones porque sólo así se asegura el progreso personal, familiar y colectivo. En medio de ese discurso que Bohórquez d-enuncia desde la parodia, podemos notar que introduce al menos cuatro voces:

${ }^{4}$ En este artículo no me ocupo de los poemas de estos dos libros debido a que está próximo a aparecer un estudio específico que destiné a dichos materiales poéticos. 
la del sonido de un reloj, la del poeta, la referencia a discursos políticos/ jurídicos y, aquellas referencias con lo popular, como es el tema de canciones, porras o pensamientos monológicos de la clase trabajadora. La polifonía de este poema le otorga un carácter teatral que facilita incluso una posible puesta en escena.

El título "Día franco" alude al lenguaje del descanso en la milicia, instancia que dentro del poema queda revelada por la vigilancia y control de los ciudadanos. Por su parte, el sonido del reloj marca el tiempo real que va de las dos a las cinco horas, pero también marca el tiempo histórico y sus acontecimientos.

En el ámbito internacional, Bohórquez refiere acontecimientos posteriores a la Segunda Guerra Mundial: la guerra de Biafra, ciudad nigeriana que en 1967 inició una cruenta guerra civil debido a sus intereses de independizarse de Nigeria, ya que la ciudad es una de las regiones más importantes en yacimientos petroleros de África. La desestabilización social cobró en sólo ocho meses la vida de más de dos millones de personas, porque más allá del conflicto civil, el patrocinio bélico de las compañías petroleras internacionales fue considerable. Otros acontecimientos de orden internacional referidos en el poema son el asesinato del Che Guevara en Bolivia en 1967, país que en 1971 es víctima de un golpe de Estado por parte de Hugo Banzer, quien reprimió todo acto de guerrilla y revolución. La Revolución Cubana de 1959, la Guerra de Vietnam, el conflicto de los negros en Estados Unidos y la aparición de empresas transnacionales en diferentes partes del mundo son parte de la política colonizadora que silencia e instaura regímenes militares y sistemas políticos y económicos de grandes injusticias sociales e incluso daños ecológicos que son consecuencia de la guerra nuclear. El nacimiento del grupo guerrillero Tupamaros en Uruguay durante los años sesenta, o la dictadura militar de Juan Velasco Alvarado, en Perú durante 1968-1975, son algunos de los referentes obligados a los que recurre Bohórquez en un ejercicio de la memoria personal que se vuelve colectiva cuando existen interlocutores con las mismas preocupaciones. Así, desde el terreno de la poesía, el artista se pregunta cuál es la función del creador, dónde están los poetas y su compromiso con lo que sucede más allá de la palabra. La referencia intertextual paródica del poema "20" de Pablo Neruda, perteneciente a su libro Veinte poemas de amor y una canción 
desesperada (1924) tiene la función de desolemnizar a los imitadores del chileno y no al Premio Nobel de Literatura $1971 .^{5}$

\author{
Biafra... \\ qué poca cosa el corazón, \\ para qué ha de servir, \\ de qué sirvió el pendejo poema, \\ protestamos, protestamos, protes \\ dan \\ ganas de cagarse en uno mismo, \\ don \\ poeta \\ carajadita irresistible, \\ inservible \\ charlatán \\ dón \\ destarán el gran rey don nóbel, \\ dó los infantes del verso correlón, \\ qué se fizieron? \\ din, \\ Berlín, \\ dan, \\ Vietnam, \\ cantan los merolicos veinte boleros de amor \\ y otra guaracha desesperebria, \\ dan las dos también en algún sitio de América \\ donde Perú o Bolivia
}

5 Pablo Neruda fue uno de los escritores de ideología comunista más activos en cuanto a militancia y conciencia social. Abigael Bohórquez montó en poesía coral varios poemas del chileno durante las décadas de los sesenta y setenta con sus grupos de poesía coral que dirigió inicialmente en el Organismo de Promoción Internacional de la Cultura (OPIC), dependiente de la Secretaría de Relaciones Exteriores y posteriormente en Milpa Alta. La referencia al Premio Nobel quizás sea una alusión al silencio de los Premio Nobel de Literatura, el sueco Harry Martinson (1974) o al italiano Eugenio Montale (1975), ya que "Día franco" se publicó dentro de Memoria en la Alta Milpa (1975). El poema de Bohórquez habla inclusive sobre la protesta de algunos escritores en lengua española: "León Felipe protestó, / Pablo Neruda protestó, / César Vallejo protestó" (112). 


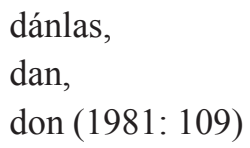

En el ámbito de lo nacional, el poeta se observa desde su voz impotente en medio de una mercadotecnia ilusoria del placer y el supuesto bienestar social, pues frente a la realidad de un país con fuertes conflictos sociales, se impone la famosa expresión de la porra usada en festividades nacionales, onomásticos y demás motivos, sólo que Bohórquez se refiere a los tres partidos políticos más importantes del momento en México y la onomatopeya guarda un cariz bélico ("bang" en lugar de "ban"), a su vez que la ruptura o separación de palabras ("danlas" por "dan las") en un sentido fonético, alude a una referencia de entrega sexual. En el siguiente ejemplo observamos el recurso de la ruptura de una voz (la del poeta) para dar paso al discurso de la festividad política dominante. El poeta toma como pre-texto la porra del equipo América, que procede de 1924:

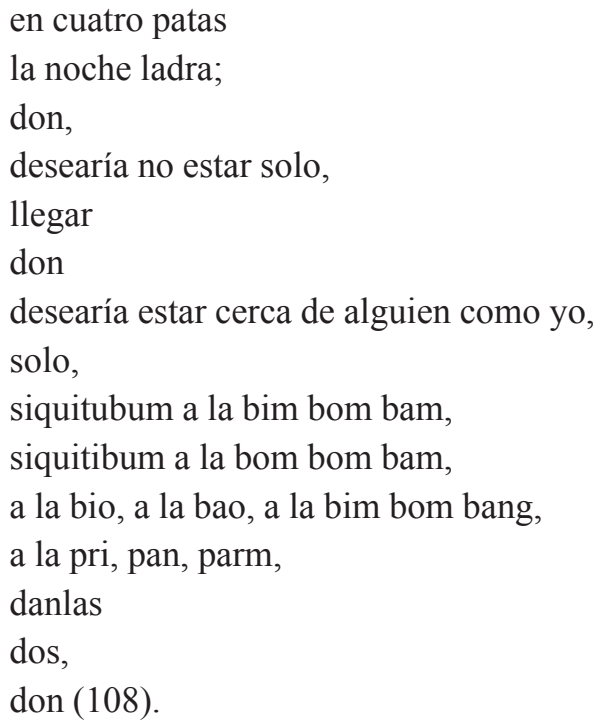

En medio de lo ilusorio y pasajero de la festividad política y del espectáculo, el poeta refiere también a la gente de la clase media que toma el camión para llegar a su escuela o trabajo, aquellos que ocupan su mente en realizaciones eróticas, mientras otros, ensimismados, piensan 
en sus deudas o en ingresar a la academia de policía, en comprarse ropa nueva, en ir al médico. En medio de las preocupaciones por las necesidades inmediatas y los sueños, el poeta introduce un verso de la famosa canción "039”, del cantante de música tropical Mike Laure: "039039 039 se la llevó" (112). Para mitigar las preocupaciones sobre la pobreza social, el caos nacional e internacional, existe un aparato cultural popular que entretiene y hace olvidar a la gente su condición menesterosa.

En este caso, a diferencia de otros poemas más combativos publicados en Acta de confirmación once años antes, aquí se tiene una visión fatalista de la realidad. Considera que incluso la poesía y la manifestación resultan insuficientes: "puedo escribir los versos más tristes esta noche / y $\tan \operatorname{tan"~(112).~Su~visión~es~catastrófica,~casi~apocalíptica,~porque~las~}$ reglas de las desigualdades sociales han permeado considerablemente la sociedad, entretenida en el consumo y en los intereses personalísimos y la subsistencia inmediata e incluso en las aspiraciones frívolas e innecesarias. El poema cierra con la siguiente estrofa: "Amigos, / son ahora las cinco. / Sueña. / Todos estamos muertos / de antemano".

Juan Bañuelos y Abigagel Bohórquez son dos poetas que más allá de compartir amistad e ideología política, son desde mi punto de vista creadores que sostuvieron una férrea batalla en contra de los postulados e intereses del canon literario que autoriza, hace o impide la promoción de la obra de otros. A la par que su compromiso con la estética poética, su voz disidente se sostiene en los discursos emergentes de la palabra que no se doblegan al poder político y cultural de los "intelectuales orgánicos". La realidad circundante se convierte en fuente de significación poética, modo de conocimiento y diálogo con la historia y su larga tradición de infamias e injusticias. Es quizás su actitud rebelde la que convierte a estos dos poetas en fuentes obligadas para la revisión de la poesía mexicana de tema social durante el siglo XX.

BIBLIOGRAFÍA

Bañuelos, Juan. Vivo, eso sucede. México: Fondo de Cultura Económica, 2012.

Bohórquez, Abigael. Ensayos poéticos. México: Élite, 1955. 
Bohórquez, Abigael. Memoria en la Alta Milpa. Ilustraciones de Leopoldo Estrada. México: Federación Editorial Mexicana, 1975.

Bohórquez, Abigael. Heredad. Antología provisional (1956-1978). Prólogo de Carlos Eduardo Turón. México: Federación Editorial Mexicana, 1981.

Camacho, Daniel y Rafael Menjívar (coordinadores). Los movimientos populares en América Latina. México: Siglo XXI Editores-Universidad de las Naciones Unidas, 2005.

Cros, Edmond. Literatura, ideología y sociedad. Versión española de Soledad García Mouton. Madrid: Gredos, 1986 (Biblioteca Románica Hispánica, núm. 349).

Gutiérrez, Ángel. Los tupamaros en la década de los años sesenta. México: Extemporáneos, 1978.

Ibargoyen, Saúl y Jorge A. Boccanera. Poesía rebelde en Latinoamérica. Buenos Aires: Editores Mexicanos Unidos, 1978.

Lefèbvre, Henri. "Contenido ideológico de la obra de arte", en Adolfo Sánchez Vázquez (compilación). Antología. Textos de estética y teoría del arte. México: Universidad Nacional Autónoma de México-Coordinación de Humanidades-Dirección General de Publicaciones, 1982 (Lecturas Universitarias, núm. 14): 154-162.

Monsiváis, Carlos. Poesía mexicana II. 1915-1979. México: Promexa Editores, 1979.

Monsiváis, CARlos. "Notas sobra la cultura mexicana en el siglo xx", en Historia General de México. México: El Colegio de México, 2000.

Neruda, Pablo. Veinte poemas de amor y una canción desesperada. Buenos Aires: Seix Barral, 2002.

Neruda, Pablo. Confieso que he vivido. Edición y notas de Jorge Edwards. Barcelona: Random House Mondadori, 2004.

Ortiz Domínguez, Efrén. "Sublime abyección: La poesía de Abigael Bohórquez y Juan Bañuelos". Artículo disponible en $<$ http://www.lehman.edu/ faculty/guinazu/ciberletras/v11/ortizdominguez.html $>$ [Fecha de consulta: 2 de agosto de 2015].

Paz, Octavio, Alí Chumacero, José Emilio Pacheco y Homero Aridjis. Poesía en movimiento. México 1915-1966. Prólogo de Octavio Paz. México: Siglo XXI Editores, 2006.

Reyes, Juana. “Abigael Bohórquez, el poeta 'anónimo' del siglo xx", en Expediente Ultra, año V, época II, núm. 69 (octubre de 2014): 8-11.

Robin, RÉGINE. "Para una sociopoética del imaginario social", en Françoise Perus (coompiladora). Historia y literatura. México: Instituto Mora, 2001.

Serna, Enrique. Genealogía de la soberbia intelectual. México: Taurus, 2013. 
Gerardo Bustamante Bermúdez

Doctor en Letras por la Universidad Nacional Autónoma de México. Maestro en Letras Mexicanas por la misma institución y Licenciado en Letras Hispánicas por la Universidad Autónoma Metropolitana, Iztapalapa. Ha publicado una veintena de artículos críticos en revistas especializadas y libros colectivos sobre la obra de Heriberto Frías, Elena Garro, Carlos Fuentes, Amparo Dávila, Rosario Castellanos, Pedro Lemebel, José Donoso, Reinaldo Arenas, Delfín Prats, Abigael Bohórquez, entre otros. Se dedica a los estudios sobre masculinidades disidentes en la literatura latinoamericana de los siglos XX y XXI. Es profesor-investigador de la Universidad Autónoma de la Ciudad de México, en la Licenciatura en Creación Literaria. 